\title{
ANALYSIS OF THE PHOTOSYNTHETIC PARAMETERS, THE YIELD AND THE QUALITY OF WINTER WHEAT
}

\author{
József Csajbók ${ }^{1}$, Erika Kutasy ${ }^{1}$, Péter Pepó ${ }^{1}$ \\ ${ }^{1}$ University of Debrecen, Böszörményi Street 138. Debrecen, Hungary, e-mail: csj@agr.unideb.hu
}

Keywords: wheat, quality, photosynthesis, nutrient supply

\section{SUMMARY}

\begin{abstract}
The environmental adaptability of crop production is basically determined by the selection of biological background (plant species and varieties) suitable for the region and the site. The aim of our work is to parametrize the plant assimilation, its intensity, dynamics and the most important characteristics and the relationships to the quality in winter wheat trials. The measurements were carried out at the research site of the University of Debrecen in small parcel experiments. We measured the leaf net $\mathrm{CO}_{2}$ assimilation rate, stomatal conductance, intercellular $\mathrm{CO}_{2}$ level, the transpiration, the leaf temperature and the air temperature by the LICOR LI-6400 portable photosynthesis system in field trials on the nutrient supply. The soil of the experimental area is calciferous chernozem with favorable water regime.

We have examined the photosynthetic activity, the productivity and yield stability of winter wheat varieties. We have compared the yield results, at similar agrotechnical conditions in seven cropyears. We also determined the quality parameters of the winter wheat varieties. Then we valued the yield stability of genotypes with the help of analysis of variance and linear regression equations. We have defined the connections between assimilation parameters, the yield stability and quality parameters of wheat varieties.
\end{abstract}

\section{Introduction}

Our research objectives were to determine the relationships between the nutrient supply, the photosynthetic parameters, yield quantity and quality of different winter wheat varieties via small- plots field trial on nutrient supply. From the external elements, the climatic conditions have the largest effect. We examined the photosynthesis of winter wheat at different nutrient supply in seven years.

Researchers studied the influencing factors of the photosynthesis system of the crops from different aspects. Bindraban (1999) found that the photosynthesis of wheat depends mainly on the light intensity and the effect of nitrogen supply is low. Vidal et al. (1996) estimated, that in consequence of the tripling the light intensity, the photosynthesis intensity was doubled. Shangguan et al. (2000), Futó (2003) agreed that the nitrogen and water supply have great effect on the photosynthetic gas exchange. The higher nitrogen supply lowered the water use efficiency of the plants and the net photosynthetic rate decreased. The effect of nitrogen nutrition on photosynthetic characteristics was not identical under different water status. Fernandez et al. (1996) monitoring physiological parameters (leaf water potential, leaf conductance and net photosynthesis rate) showed that water relationships of maize were not affected by the reduced $\mathrm{N}$ fertilization. Plant reproduction is sensitive to water deficits, and in maize the water deficits inhibit photosynthesis (Boyer-Westgate, 2004). Under N stress photosynthesis was reduced by a decreased light absorption and by the decreased utilization of assimilates (de Groot et al. 2003). Schmitt-Edwards (1981) data indicate that C4 species maize had greater nitrogen use efficiency than either the two C3 species examined. Csajbók et al. (2007) write that the differences between plant species in photosynthesis were significant but not in every cases. Changing the illumination intensity caused significant differences in the net photosynthesis rate. The $\mathrm{CO} 2$ assimilation of the maize was higher than potato or winter wheat above $500 \square$ mol photon m-2s-1 light intensity.

\section{Materials and methods}

The varieties belong to different ripening class under uniformed technology in 7 cropyears between 2001 and 2007. The observation was carried out at the Látókép Plant Cultivation Research Site of the Centre for Agricultural and Applied Economic Sciences, University of Debrecen.

The soil of the experimental area is calciferous chernozem. Its physical characteristics are that of semi compacted clay category. The thickness of the humus stratum is around 70-80 of which the evenly humidified stratum is about $40-50 \mathrm{~cm}$ thick. The humus content of the evenly humidified layer is $2.5-3.4 \%$. The soil specific plasticity index (KA) was 43 , the $\mathrm{pH}$ value was nearly neutral $(\mathrm{pHKCl}=6.46)$. The phosphorus content of the soil was medium (the value of AL-soluble $\mathrm{P}_{2} \mathrm{O}_{5}$ was $133 \mathrm{mg} / \mathrm{kg}$ ), the degree of potassium supply was fairly-good (the value of AL-soluble $\mathrm{K}_{2} \mathrm{O}$ was $240 \mathrm{mg} / \mathrm{kg}$ ).

Examining the water conditions of the soil, it can be stated, that it is typical to the chernozem soils, i.e. has favorable water regime, excellent water holding capacity $(808 \mathrm{~mm}$ in the $0-200 \mathrm{~cm}$ layer), unavailable water content is $295 \mathrm{~mm}$ in the $0-200 \mathrm{~cm}$ layer, the amount of disponible water in saturated state is $513 \mathrm{~mm}$ in the 0 $200 \mathrm{~cm}$ layer of which 342 is readily available. The watertable is at 8-10 meters depth.

The small-plot experiments were set up in split-plot arrangement with four repetitions. In each experimental year we applied the same fertilizer dosage. The forecrop was sweet corn in each year. The gross area of a parcel 
was $18 \mathrm{~m} 2$ in the split-plot design. In the experiment we have tested the following wheat varieties: GK Öthalom (2001-2007), Lupus (2001-2007), Fatima 2 (2001-2005), Mv Mazurka (2006-2007).

Applied fertilizer doses (active agent kg ha-1) $(2001-2007$, Debrecen)

\begin{tabular}{|c|c|c|c|c|}
\hline & $\mathrm{N}$ & $\mathrm{P}_{2} \mathrm{O}_{5}$ & $\mathrm{~K}_{2} \mathrm{O}$ & Sum \\
\hline control & 0 & 0 & 0 & 0 \\
\hline 1 & 30 & 22,5 & 26,5 & 79 \\
\hline 2 & 60 & 45 & 53 & 158 \\
\hline 3 & 90 & 67,5 & 79,5 & 237 \\
\hline 4 & 120 & 90 & 106 & 316 \\
\hline 5 & 150 & 112,5 & 132.5 & 395 \\
\hline
\end{tabular}

Assimilation parameters were measured in the field with a LICOR 6400 portable photosynthesis system. We measured the leaf net $\mathrm{CO}_{2}$ assimilation rate, stomatal conductance, intercellular $\mathrm{CO}_{2}$ level, the transpiration, the leaf temperature and the air temperature, air pressure. Light changes will cause immediate photosynthetic rate changes therefore the light was controlled and stable in the sample chamber. We used $2000 \mu \mathrm{mol}$ photon $\mathrm{m}^{-2} \mathrm{~s}^{-1}$ photosynthetic active radiation (PAR) with $90 \%$ red $(630 \mathrm{~nm})$ and $10 \%$ blue $(470 \mathrm{~nm})$ light. We measured six times per leaf, in four repetitions.

The measurements of quality parameters were performed at the Institute of Food sciences, Quality assurance and Microbiology, Centre for Agricultural and Applied Economic Sciences, University of Debrecen. The values of wet gluten contents, gluten elasticity values, farinograph index and the Hagberg Falling Number were determined according to the Hungarian standards (MSz ISO 5531: 1993, MSz 6369-5: 1987, MSz ISO 55303:1994 and the MSz ISO 3093: 1995, respectively).

We analyzed and evaluated the data of experimental results with the SPSS 13.0 statistical software package. The accuracy of the statistical analysis were given at the level of LSD5\% according to the method of Sváb (1981).The results were evaluated with analysis of variance, and Pearson's correlation analysis.

Weather of the experiment years was very different. There were unfavorable weather conditions i.e. long drought periods in 2003 and 2007, with weaker vegetative developments and low yields, favorable weather conditions with excellent vegetative developments and excellent yields in 2004 and 2005, nearly average weather conditions with fairly good yields in 2001, 2002 and 2006.

\section{Results and Discussion}

Comparing the data of varieties, we can see that there are significant differences in the net photosynthesis rate between the varieties in all of the seven years with 5\% error level. After data processing we found that there were significant differences on $\mathrm{P}=0.1 \%$ level in the net photosynthesis, the stomatal conductance and transpiration between the nutrient levels in every year. Figure 1 shows the effect of nutrient supply on the photosynthesis intensity.

The photosynthesis intensity of Mv Mazurka variety was remarkably higher than the others at better nutrient supply levels.

The maximum photosynthetic activity was detected at $\mathrm{N}_{60} \mathrm{P}_{45} \mathrm{~K}_{53} \mathrm{~kg}$ ha $^{-1}$ in case of the four varieties (Figure 1). The photosynthetic gas exchange parameters of wheat are remarkably improved by nutrient supply in well watered conditions. The water stress through decreased stomatal conductance has significant negative effect on the assimilation parameters.

The highest photosynthetic intensity we measured in 2005 and 2004 years (Table 2). In these years was favorable weather conditions and the yield was the highest, but we did not find correlations between the yield and photosynthesis intensity except the GK Öthalom variety.

Average of net photosynthesis rate of the winter wheat $\left(\mu \mathrm{mol} \mathrm{CO} \mathrm{C}^{-2} \mathrm{~s}^{-1}\right)(2001-2007$, Debrecen)

\begin{tabular}{|l|c|c|r|}
\hline Year & Mean & Std. Deviation & \multicolumn{1}{|c|}{$\mathrm{N}$} \\
\hline 2001 & 16.392 & 3.0226 & 432 \\
\hline 2002 & 21.912 & 5.5121 & 1296 \\
\hline 2003 & 16.106 & 5.8088 & 432 \\
\hline 2004 & 26.643 & 6.1719 & 1296 \\
\hline 2005 & 27.239 & 3.9040 & 216 \\
\hline 2006 & 20.680 & 3.2798 & 648 \\
\hline 2007 & 18.388 & 5.8518 & 648 \\
\hline Total & 21.051 & 4.7930 & 4968 \\
\hline
\end{tabular}


According to the evaluation of the quality parameters it can be stated that the wet gluten content of $\mathrm{Mv}$ Mazurka was the highest on every fertilizer level in average, but it was only in 2006, 2007 in the experiment (Figure 3). There are no significant differences between GK Öthalom and Lupus in the Hagberg Falling Number, Mv Mazurka has the highest values (436-475 s) and the Fatima 2 the lowest (278-312 s).

Table 3

Correlations between the fertilization, the yield, the quality, and the assimilation parameters of wheat (2001-2007, Debrecen)

\begin{tabular}{|l|c|c|c|c|c|c|c|}
\hline & Yield & Photo & Trans & WGC & GEV & Farin & Fall \\
\hline Fert & $0.81^{*}$ & -0.01 & 0.28 & $0.54^{*}$ & 0.47 & $0.60^{*}$ & 0.21 \\
\hline Yield & 1 & -0.03 & $0.66^{*}$ & 0.27 & 0.24 & 0.30 & -0.10 \\
\hline Photo & & 1 & -0.41 & $0.69^{*}$ & $0.54^{*}$ & $0.51^{*}$ & $0.78^{*}$ \\
\hline Trans & & & 1 & -0.21 & -0.24 & -0.21 & $-0.58^{*}$ \\
\hline WGC & & & & 1 & $0.85^{*}$ & $0.93^{*}$ & $0.85^{*}$ \\
\hline GEV & & & & & 1 & $0.92^{*}$ & $0.64^{*}$ \\
\hline Farin & & & & & & 1 & $0.76^{*}$ \\
\hline Fall & & & & & & & 1 \\
\hline
\end{tabular}

Pearson- correlation coefficients, $*$ Correlation is significant at the 0.05 level (2-tailed).

Fert: fertilization doses, Photo: photosynthetic activity, Trans: transpiration, WGC: wet gluten contents, GEV: gluten elasticity values, Farin: farinograph index, Fall: Hagberg Falling Number

Figure 1: Photosynthetic activity of winter wheat varieties (2001-2007, Debrecen)

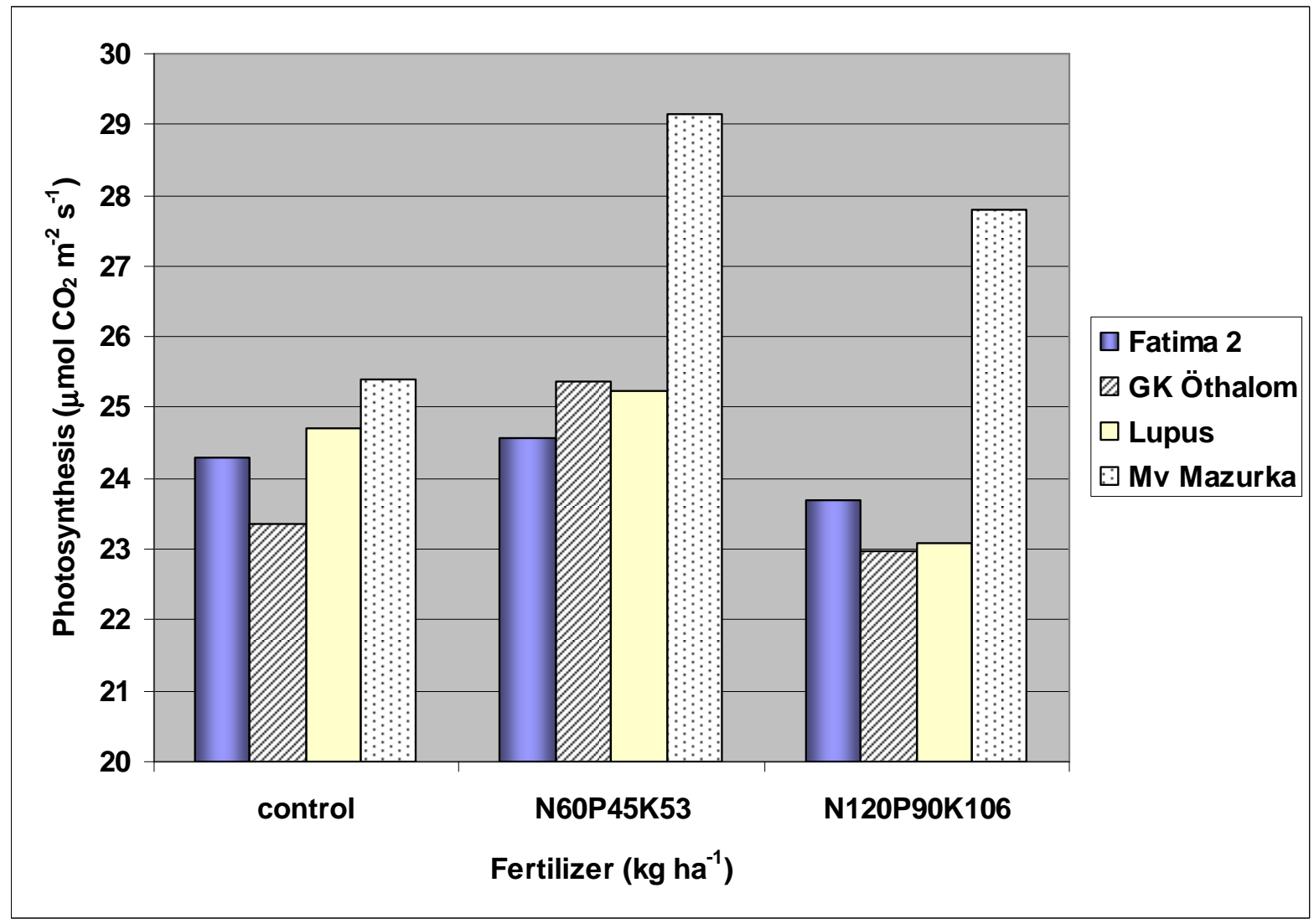


Figure 2: Average yield of winter wheat varieties (2001-2007, Debrecen)

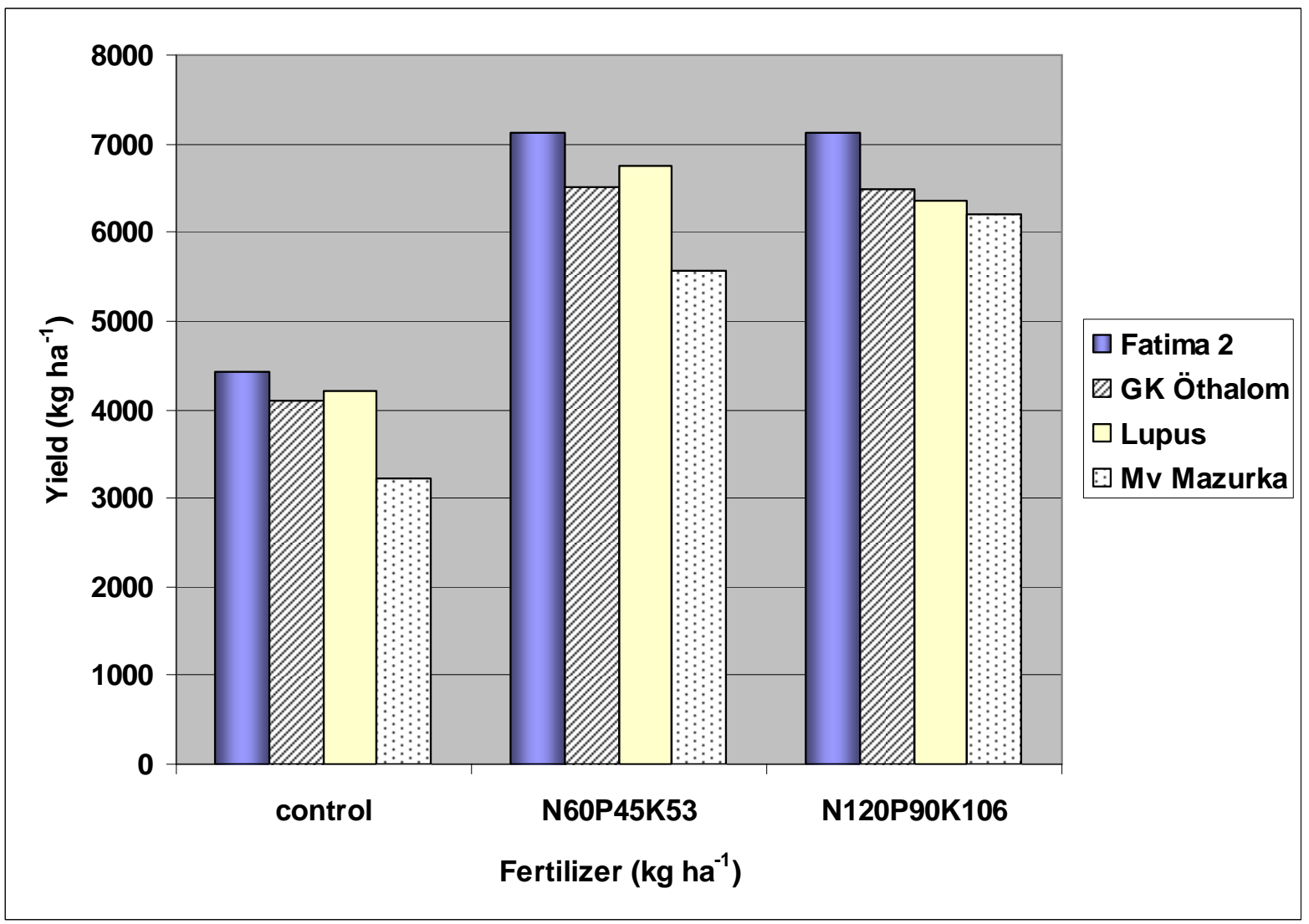

Figure 3: Average wet gluten content of winter wheat varieties (2001-2007, Debrecen)

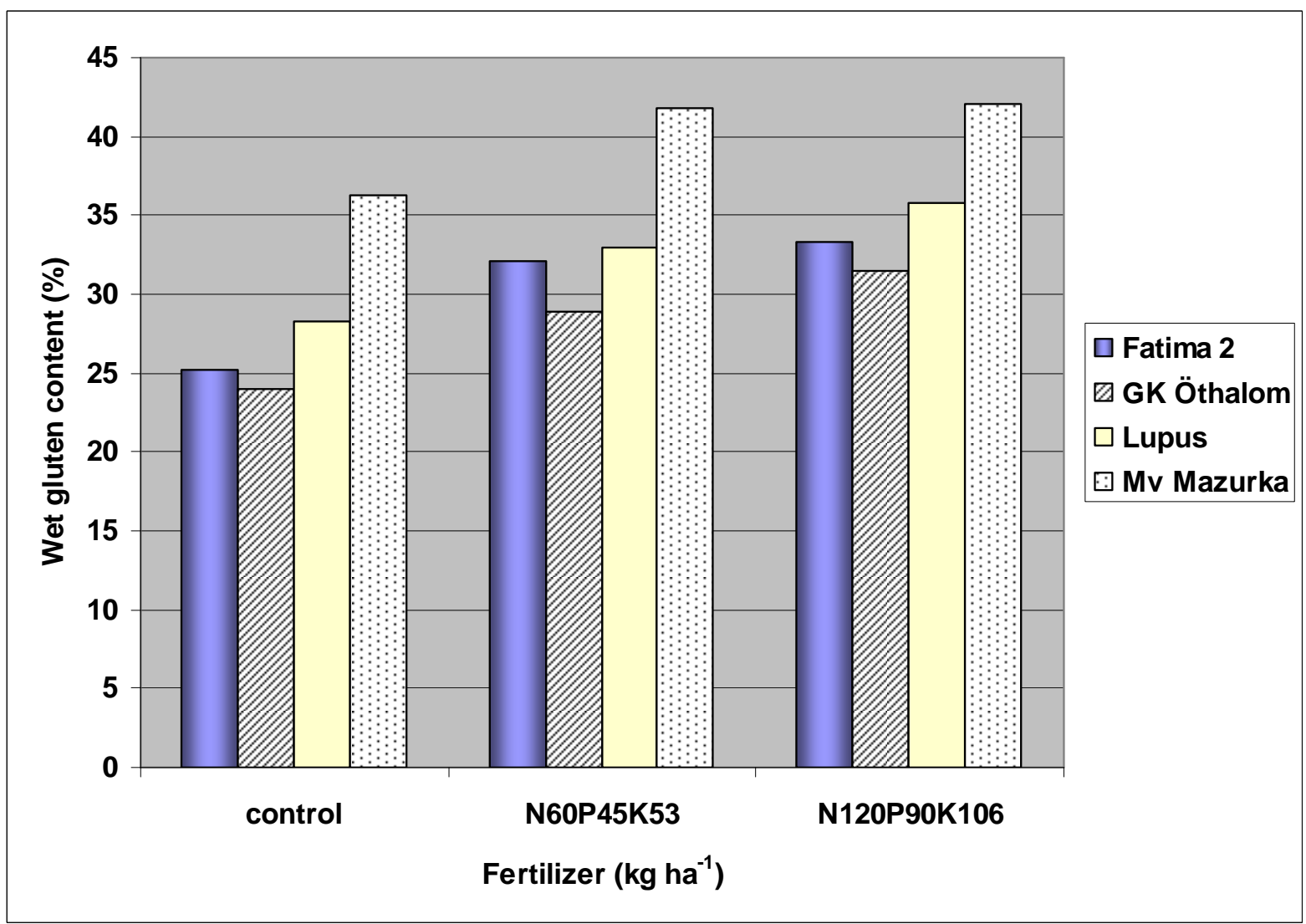




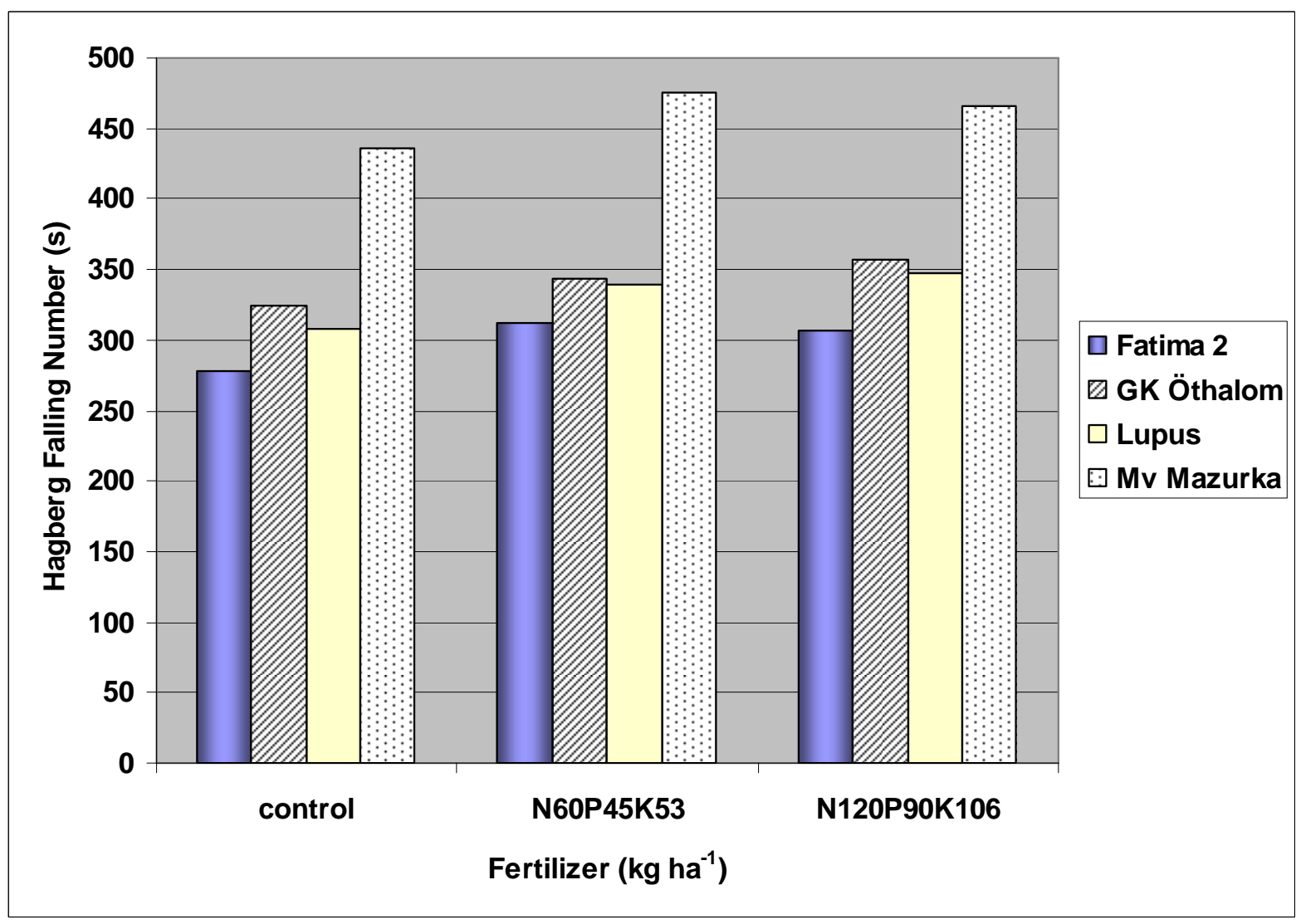

Coming up to our expectations the fertilization has significant effect on the yield $(\mathrm{r}=0.81)$ and also the quality parameters $(\mathrm{r}=0.21-0.60)$. There was no correlation between the net photosynthesis rate and the fertilization level $(\mathrm{r}=-0.01)$ and was weak correlation between the transpiration rate and fertilization $(\mathrm{r}=0.28)$ (Figures 1-5).

Our measurements show strong connections between the measured quality parameters of winter wheat (Table $3)$. There is very close, positive, significant correlation between the wet gluten contents and farinograph index $(\mathrm{r}=0.93)$, between the gluten elasticity values and farinograph index $(\mathrm{r}=0.92)$. There is close, positive, significant correlation between the wet gluten contents and the gluten elasticity values $(r=0.85)$, between the wet gluten contents and the Hagberg Falling Number $(\mathrm{r}=0.85)$, between the farinograph index and the Hagberg Falling Number $(\mathrm{r}=0.76)$. There is medium positive correlation between the gluten elasticity values and the Hagberg Falling Number $(\mathrm{r}=0.64)$.

As we analyzed the correlations between the assimilation parameters and the yield and quality of wheat, we could see that there is no correlation between net photosynthesis rate and yield ( $r=-0.03)$, but there is medium, positive, significant correlations between the transpiration level and the yield $(r=0.66)$.

There are medium to close correlations between the net photosynthesis rate and the quality parameters. There is close, positive, significant correlation between net photosynthesis rate and the Hagberg Falling Number $(\mathrm{r}=0.78)$. There are medium, positive, significant correlations between the net photosynthesis rate and the wet gluten contents $(\mathrm{r}=0.69)$ the farinograph index $(\mathrm{r}=0.51)$, and the gluten elasticity values $(\mathrm{r}=0.54)$.

Between the transpiration values and the Hagberg Falling Number there is negative medium correlation ( $\mathrm{r}=-$ 0.58). That means, that the better water conditions could cause higher enzyme activity and lower falling number in winter wheat- as show the results of our experiments.

\section{Conclusions}

The results show that there are significant differences in the net photosynthesis rate, the stomatal conductance and transpiration between the varieties and can be found significant differences also between the nutrient levels in every year.

Our measurements show strong connections between the measured quality parameters of winter wheat varieties.

Medium to close correlations can be found between the net photosynthesis rate and the quality parameters in the analyzed years. 


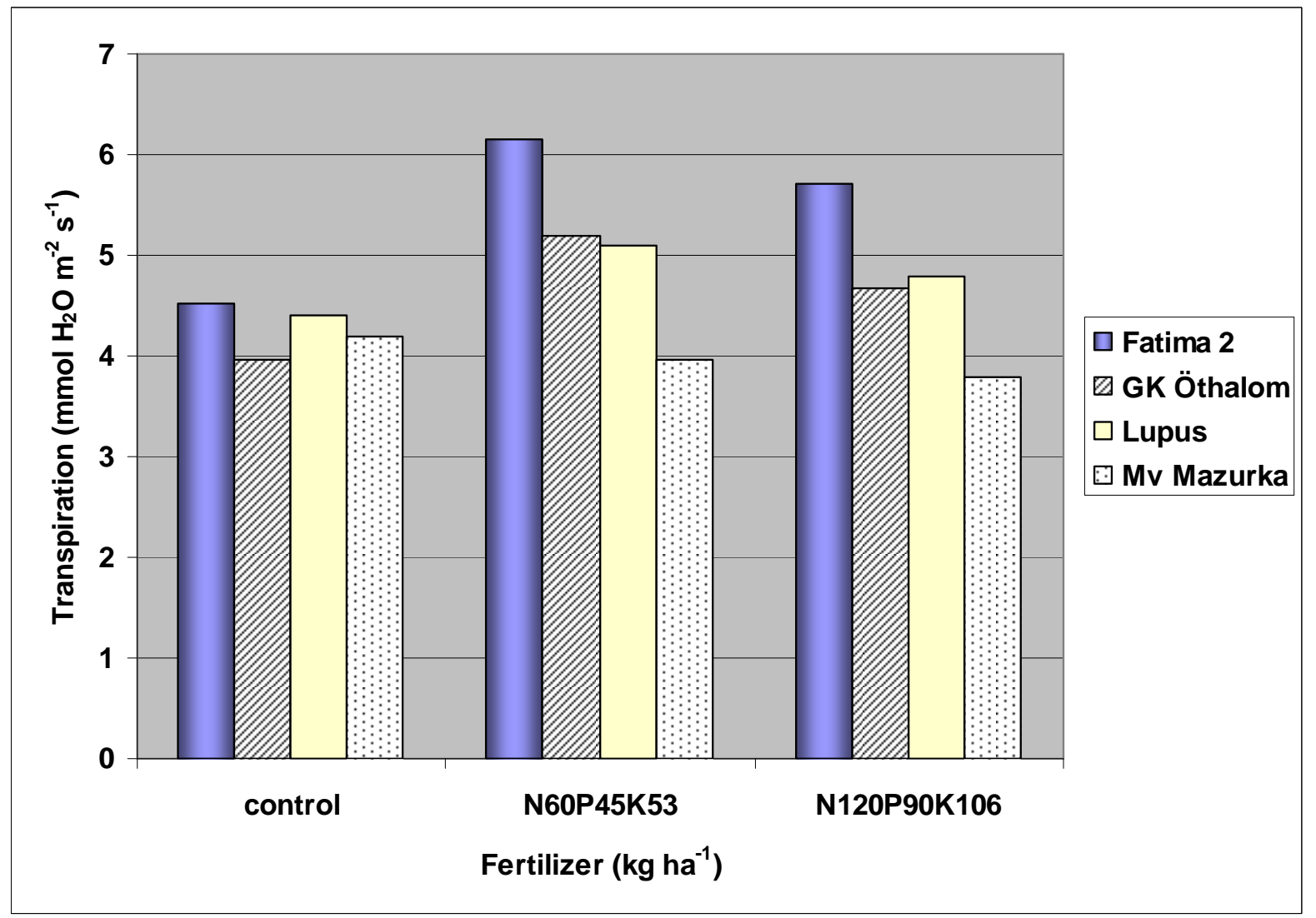

\section{REFERENCES}

1. Bindraban, P. S. 1999. Impact of canopy nitrogen profile in wheat on growth. Field Crops Research 63: 63-77.

2. Boyer, J. S. - Westgate, M.E. 2004. Grain yields with limited water. J. of Exp. Botany, 55: 2385-2394.

3. Csajbók J.- Kutasy E. -Hunyadi Borbély É. - Mrs. M. Lesznyák 2007. Comparing the photosynthetic activity of maize, winter wheat, potato and some significant weed. Cereal Research Communications, 35:(1) 325-328.

4. De Groot, C. C. et al. 2003. Contrasting effects of $\mathrm{N}$ and $\mathrm{P}$ deprivation on the regulation of photosynthesis in tomato plants in relation to feedback limitation. J. of Experimental Botany, 54: 1957-1967.

5. Fernandez J.E. et al. 1996. Water use and yield of maize with two levels of nitrogen fertilization in SW Spain. Agricultural Water Management. 29: 215-233.

6. Futó, Z. 2003. Effect of leaf area on the yield of maize in a fertilization experiment. Növényterm., 52: 317-328.

7. Schmitt, M.R. - Edwards, G.E. 1981. Photosynthetic capacity and nitrogen use efficiency of maize, wheat, and rice: A comparison between $C_{3}$ and $\mathrm{C}_{4}$ photosynthesis. J. of Experimental Botany, 32: 459-466.

8. Shangguan, Z. P., Shao, M. A., Dyckmans, J. 2000. Nitrogen nutrition and water stress effects on leaf photosynthetyc gas exchange and water use efficiency in winter wheat. Environmental and Experimental Botany 44: 141-149.

9. Sharma, P. K., Anand P., Sankhalkar, S., Shetye, R. 1998. Photochemical and biochemical changes in wheat seedlings exposed to supplementary ultraviolet-B radiation. Plant Science, vol. 132 (1) 21-30.

10. Vidal, R. 1996. Short-term effects of high light intensities on soybean nodule activity and photosynthesis. Environmental and Experimental Botany 36: 349-357. 